Studia Anglica Posnaniensia 49/3, 2014

doi: 10.1515/stap-2015-0001

\title{
THE DIALECTAL PROVENANCE OF LONDON, WELLCOME LIBRARY, MS 5262
}

\author{
LAURA ESTEBAN-SEGURA
}

University of Murcia

\begin{abstract}
This paper takes into consideration the language found in London, Wellcome Library, MS 5262, a one-volume codex from the early fifteenth century which holds a medical recipe collection. The manuscript, written in Middle English (and with a few fragments in Latin), represents a fine exemplar of a remedybook, a type of writing that has been traditionally considered to be popular. The main aim is to study the dialect of the text contained in folios $3 \mathrm{v}-61 \mathrm{v}$ in order to localise it geographically.

The methodology followed for the purpose is grounded on the model supplied by the Linguistic Atlas of Late Mediaeval English (LALME) (McIntosh et al. 1986), which consists of several stages including the completion of a survey questionnaire, the creation of the linguistic profile of the text and the application of the 'fit'-technique (McIntosh et al. 1986, vol. 1: 10-12; Benskin 1991). Extralinguistic features of the manuscript may also be taken into consideration. This comprehensive analysis will help us to circumscribe the dialectal provenance and/or local origin of the text accurately.
\end{abstract}

Keywords: dialect, provenance, Middle English, MS Wellcome 5262, LALME

\section{Introduction}

The field of English historical - particularly mediaeval - dialectology has received increased attention from scholars during the last decades with a wealth of both general and specific studies (Laing 1989b; Riddy 1991; Laing \& Williamson 1994; Dossena \& Lass 2004). ${ }^{1}$ This paper is concerned with the dialect

1 The present research has been funded by the Autonomous Government of Andalusia (grant number P07-HUM-02609) and the Spanish Ministry of Science and Innovation (grant num- 
of the text in the late Middle English manuscript Wellcome 5262 (hereafter referred to as W5262), housed in London's Wellcome Library. The "usefulness, and indeed necessity, in mediaeval studies of examining each scribal text separately as a valuable source in its own right" has been claimed elsewhere (Laing 1989b: 150), as well as the importance of micro approaches focusing on individual texts to complement large-scale analyses (Stenroos 2004: 283). Thus, the main objective is to carry out an exploratory analysis of a number of linguistic features, which are represented by specific forms or occurrences of words, of the language found in W5262 in order to localise the text geographically. Extralinguistic features of the manuscript may also be taken into account since they can provide clues to further help with the dialectal circumscription of the text.

The paper is organised as follows: an introduction to the text under study is presented in this first section; then, the methodology is explained, and the analysis and results discussed; the findings drawn from the investigation are commented upon in the conclusions. Finally, the references and appendices are supplied.

W5262 is a one-volume codex containing a collection of medical recipes which dates from the first quarter of the fifteenth century. It can be classified within the type of medical writing known as remedybooks. As Voigts \& McVaugh (1984: 21) have remarked, remedybooks were "made up mostly of treatment for ailments - or, more accurately, for symptoms - by minor surgical procedures, non-theoretical phlebotomy, cupping, dietary, prayers, charms, ritual action, and, of course, "prescriptions"”, They have been traditionally considered to belong to a popular tradition of medical writing, hence standing in opposition to academic medicine. Nevertheless, recipes were not restricted to this type of books and could be found within specialised medical treatises (for instance, those occurring in the Middle English Gilbertus Anglicus (cf. EstebanSegura 2012a)). Other remedybooks are A fifteenth-century leechbook (London, Medical Society, MS 136), ${ }^{2}$ edited by Dawson (1934), and the Liber de diversis medicinis (Lincoln, Cathedral Library, MS A.5.2.), edited by Ogden (1938).

The contents of W5262 include: a) coloured illustrations of a religious nature (representing mainly saints), which have been partially obliterated (ff. 1r-3r); b) a list of contents (ff. $3 \mathrm{v}-7 \mathrm{v}$ ); c) 133 recipes, mainly therapeutic, but also prognostic, cosmetic (those pertaining to this type can hardly be called prescriptions), etc. (ff. 8r-61v); d) an added prayer in Latin to St Kenelm, patron saint of Winchcombe Abbey, a now-vanished Benedictine abbey in Gloucestershire (f. 61v). The recipes are in English and there are some fragments in Latin as well. The text is a compilation of extracts from different sources, although se-

ber FFI2011-26492). These grants are hereby gratefully acknowledged. Some of the recipes in W5262 are also collected in this manuscript. 
lected recipes might have been copied from another composite text; in any case, the Middle English version is a translation from Latin. The value of translated texts has long been acknowledged for English historical dialectology (McIntosh et al. 1986: 4; Laing 1989a: ix-x) and dialectal studies focusing on Middle English versions and/or translations of medical texts from Latin have been recently carried out (Marqués-Aguado 2009; Esteban-Segura 2010, 2012b).

Finally, it should be noted that the manuscript under consideration is unique not only for linguistic or content investigation, but also for the insights that it can provide into socio-historical aspects, as well as for its coloured drawings, rubricated initials and extravagantly decorated catchwords. ${ }^{3}$ In fact, W5262 was "item of the month" in February 2010 at the Wellcome Library as "a rare surviving devotional recipe manuscript" combining "folk remedies with religious iconography and a royal heritage to boot". ${ }^{4}$

\section{Methodology}

The methodological approach follows the model offered in the Linguistic Atlas of Late Mediaeval English (McIntosh et al. 1986), LALME for short, in which a number of steps needs to be completed. In a previous stage, the text had been transcribed from the digitised images of the manuscript, ${ }^{5}$ making every effort to produce a diplomatic transcript that would render W5262 a proper historical witness and an acceptable source of data for (historical) linguistic research. This involved the avoidance of any emendation, any modernisation (which in accordance meant keeping the symbols for thorn and yogh, and both the original capitalisation and punctuation practice), any alteration of scribal word division or separation, and finally, any form of regularisation. ${ }^{6}$ Returning to $L A L M E$ and its procedure, the first step entails filling in a survey questionnaire, which consists of items and their different forms of realisation. A set of items was selected from the comprehensive list supplied in volume 3 of LALME (pp. xviii-xix) in order to devise the linguistic profile (LP henceforward) of the text. They mostly comprised function words, although some content words and inflections have also been included. As well as having been transcribed, W5262 had been previously lemmatised and morphologically tagged, as part of the work done for several research projects based at the University of Málaga (Spain) in which the author

For further details about the manuscript, see Esteban-Segura (2013).

http://blog.wellcomelibrary.org/2010/02/quick-fixes-saints-and-symbolism-a-rare-

surviving-devotional-recipe-manuscript-from-the-early-15th-century-item-of-the-monthfebruary-2010/ (Last accessed 15 March, 2013).

5 The text remains unedited to date; its edition is currently in preparation.

$6 \quad$ In this respect, see Lass (2004: 22), who advocates the "maintenance of forensic cleanliness in a field full of potentially corrupted information sources". 
collaborates. ${ }^{7}$ The lemmatisation and morphological tagging of the text eased considerably the retrieval of all the occurrences (or forms) of items, which were promptly obtained. The software tool Text Search Engine (Miranda-García \& Garrido-Garrido 2012) was used for the purpose. With regard to the arrangement of results, LALME's bracketing system (see vol. 3: xiv) has been modified. Thus, all the corresponding forms of each item are supplied with the number of occurrences in decreasing order of frequency. The completed questionnaire has allowed devising the LP of W5262, which is available in Appendix I.

In the next stage, the 'fit'-technique (McIntosh et al. 1986, vol. 1: 10-12; Benskin 1991) was applied. This technique encompasses in turn different phases, in which dot maps, item maps, LPs of other texts and the county dictionary may be employed and/or consulted. Firstly, dot maps (vol. 1) are used to plot forms so as to delimit an approximate geographical area of origin; then, item maps (vol. 2) are assessed for closer dialectal localisation, as they present in more detail subareas in which specific variants are registered. The final stage in the dialectal localisation is to collate the LP obtained with the LPs (vol. 3) for the surrounding survey points in order to find forms having close congeners in them and, therefore, to confirm and exactly pinpoint the area. The county dictionary (vol. 4) may also be consulted for recalcitrant variants or forms not gathered in maps.

Following these principles, well-attested forms from the LP of W5262 were selected and compared against the dot maps found in LALME's volume 1. Then, to restrict the area of provenance and find the precise location of items' variants, a set of them was chosen (those considered to have diagnostic value, inasmuch as their forms might contain distinctive features) and scrutinised against the corresponding item maps by means of an overlay of tracing paper in which dominant and minor variants were recorded. Lastly, the LP was compared with other LPs contained in LALME.

\section{Analysis}

Once the features had been surveyed in the dot maps, the distribution of the (primary) variants for items ${ }^{8}$ ANY, MUCH, THOUGH, ADDER, together with the secondary variants (represented by those forms ending in $\langle\mathrm{p}>$ for the plural) of WILL and SHALL, ${ }^{9}$ restricted the geographical location of the text to the Mid-

\footnotetext{
The main aims are the production of digital editions and the compilation of the annotated Málaga Corpus of Late Middle English Scientific Prose, which can be consulted at the web page http://hunter.uma.es.

8 Items are rendered in small capitals and forms in single inverted commas, although they are not used for the forms in the appendices.

9 Dominant or primary forms or variants are the most frequent ones; less common forms are
} 
lands and South. Personal pronouns were of use for determining a more specific - although still broad - localisation; accordingly, the dominant forms of items for the nominative (THEY) and objective (THEM) case ('pei' and 'hem' respectively) ${ }^{10}$ of the third-person plural pronouns correspond to a mixed type (with a Scandinavian subject form and a native object form), which is distinctive of the Midlands (Mossé 1952: 55, 58). Moreover, the absence of prefixal marking for past participles (42 out of 124 instances of past-participle forms are prefixed, while the rest (80×) appear without a prefix) and the use of the prefix $y$-in past participles, which is found on 31 occasions, are also typical of the Midlands (Mossé 1952: 86).

The area in which the forms belonging to the items previously mentioned conflate the most and in which there is a greater concentration of them is the West Midlands. This specific localisation has been further corroborated by the primary forms for EACH ('uche' and 'vche'), which are to be found almost exclusively in this region. Other items such as THE, IT, WAS, WOULD, FROM, THAN, THERE or WHERE were of no account, given that the forms present in W5262 are widespread all over the country.

Several items from the LP were selected in order to record the occurrence of their forms (both dominant and minor variants) in LALME's item maps and to further narrow down the area and establish a more specific geographical placing of the text. The first that will be mentioned is the item ARE, corresponding to the present indicative plural of the verb 'to be'. All the forms recorded in the manuscript ('beo', 'bup', 'ben', 'bep', 'beop') can be found to the north of Herefordshire (Hrf). ${ }^{11}$

Although the singular forms collected for WILL and SHALL are widespread and therefore irrelevant for precise localisation, the plural ones are revealing. Concerning the plural of the verb WILL, the 'wol' type forms ending in $\langle\mathrm{p}\rangle$ are typical of the West Midlands and all the forms occurring in the text ('wollep', 'wolle', 'wollen') can be found to the north of Herefordshire and to the north of Worcestershire (Wor). The same applies for the plural forms of SHALL ending in $<\mathrm{p}>$, which can be found bordering these two areas: in the north-western part of Worcestershire and north-eastern part of Herefordshire.

As for the plural of the noun EYE, the dominant spelling 'eẏnen' is found in the north-western part of Worcestershire, as well as the secondary variant 'eẏen'; the variant 'ýzen', of which there is only one occurrence, is attested in nearby north-east Herefordshire. Both dominant and secondary forms of the item IF ('zif', 'zef', 'if', 'yf') are found in these counties.

regarded as minor or secondary variants.

These are the dominant or primary variants.

All counties are provided with an abbreviation in $L A L M E$, which is also offered here. 
The distribution of the noun FIRE is similar but it also includes the southern parts of Shropshire (Sal) and Staffordshire (Stf). Forms of the item LITTLE can also be found in bordering Gloucestershire (Gl) and Warwickshire (Wrk).

Of all of these areas, Herefordshire and Worcestershire are the counties in which main and secondary variants of more items conflate. In this line, as Benskin (1991: 13) has pointed out, particular combinations or co-occurrences designate specific areas, which would stand for sectors in a continuum of regional dialect. This notion of a continuum also applies when considering the forms which are attested in several locations and are, consequently, shared.

In order to complete the last stage of the 'fit'-technique, the LPs from Herefordshire (vol. 3, pp. 161-175) and Worcestershire (vol. 3, pp. 550-564) were surveyed and contrasted with the LP of W5262. Those which display more similarities are LP 7460 (an early fifteenth-century manuscript including part of the New Testament), LP 7520 (a version of the Wycliffite New Testament), both from Herefordshire, and LP 7630 (a religious manuscript containing lives of saints), from Worcestershire. ${ }^{12}$

Concerning extralinguistic features, there are several sixteenth-century inscriptions in W5262 which give insights on the history or provenance of the manuscript. One of these, on folio 12r, makes reference to a man named Henry Dyngley, who belonged to a family of devout Catholics and rural farmers working as doctors and who was from Charlton, in Worcester. At the end of the manuscript, on folio 61v, there is a reference to St Kenelm, an Anglo-Saxon saint venerated throughout mediaeval England who, according to legend, died in Worcestershire. The manuscript was in physical circulation (and used) in this area and hence a historical connection with it can also be ascertained.

\section{Conclusions}

In the present study, a dialectal analysis of a medical text in late Middle English has been carried out by means of the methodology postulated in LALME. On account of the results it should be pointed out that the number of general features found throughout the country indicates that the language of W5262 is fairly standardised. Nonetheless, the data obtained from linguistic profiling and dialectal fitting suggest that it was written in the Midland variety and could be circumscribed in the West Midlands.

The conflation of forms in the counties of Herefordshire and Worcestershire has made it possible to arrive at a more specific localisation, a bordering area between these two regions being an eligible place of origin for the text of the

12 These LPs are furnished in Appendix II (LP 7460), Appendix III (LP 7520) and Appendix IV (LP 7630). Only those items shared with the LP of W5262 have been included. 
manuscript. The fact that the distribution of the forms in the LP of W5262 matches (although not in its entirety) those of three LPs from the abovementioned counties can be grounded reason to assign the dialect to the proposed area. The texts could then be viewed as forming part of a continuum, in which some forms co-occur whereas others do not. Extralinguistic aspects of the book concerning provenance and content also corroborate the placing arrived at in this study.

In spite of this ascription, it might be possible to find different dialectal layers in the text, since the scribe might have translated the language of the exemplar into his own dialect. The influence of neighbouring areas may also be significant, as has become patent in the examination of the LP (cf. the idea of a dialect being an "assemblage of linguistic components" (Benskin 1991: 23)).

Future research will address the geographical dissemination of the work. Thus, further investigation on its transmission in order to firstly find out the number of extant copies containing it or parts of it, and/or material sharing the recipes, is mandatory. This can be a difficult task since, as Mäkinen (2004: 144) argues, medical recipes in the Middle Ages constitute a close-knit textual type with a small number of original texts in which intertextuality is unavoidable.

Secondly, analyses of the language of these copies, and more specifically, of their dialects will be pursued. This can shed light on the production and circulation of medical texts during the Middle Ages. Previous studies on other scientific manuscripts and texts from the East Midlands have established the existence of an extensive output and wide diffusion of medical texts in that particular area during the mediaeval period (Jones 2000; cf. Esteban-Segura 2010, 2012b). It would be enlightening to detect whether there was a similar network in the West Midlands and, if such is the case, to assess the extent of it. 


\section{APPENDIX I}

\section{LP W5262}

THE: pe (522×), the $(1 \times)$, po $(1 \times)$, p $(1 \times)$ THESE: peose $(4 \times)$, pese $(3 \times)$, puse $(1 \times)$ IT: hit (422×), it (54×), hỳt (3×), hit (1×) THEY: pei $(9 \times)$, peẏ $(3 \times)$, paẏ $(1 \times)$, pey $(1 \times)$ THEM: hem $(79 \times)$, hem $(8 \times)$

SUCH: suche $(1 \times)$

EACH: uche $(17 \times)$, vche $(4 \times)$, eche $(1 \times)$, uch $(1 \times)$

MANY: mony் $(2 \times)$

ANY: eny் $(8 \times)$, anẏ $(2 \times)$, ani $(1 \times)$

MUCH: muche (52×)

ARE: beo $(4 \times)$, bup $(4 \times)$, ben $(3 \times)$, bep $(2 \times)$, beop $(1 \times)$

WERE: were $(4 \times)$

IS: is $(69 \times)$, ys $(11 \times)$, es $(1 \times)$

WAS: was $(6 \times)$

SHALL sg.: schal $(41 \times)$, schalt $(6 \times)$, schat (1×); pl.: schul $(4 \times)$, schullup $(2 \times)$, schelen $(1 \times)$, schullen $(1 \times)$

SHOULD: schuld $(1 \times)$

WILL sg.: wol $(21 \times)$, wel $(1 \times)$, wilt

$(1 \times)$, wolt $(1 \times)$; pl.: wollep $(2 \times)$, wolle

$(1 \times)$, wollen $(1 \times)$

WOULD: woldest $(1 \times)$

FROM: from $(5 \times)$

AFTER: aftur (12×), Aftur $(1 \times)$

THAN: pan $(1 \times)$

THOUGH: pah $(1 \times)$, pauz $(1 \times)$, pauzh $(1 \times)$

IF: zif $(45 \times)$, zef $(4 \times)$, if $(2 \times)$, yf $(1 \times)$

AGAINST: a zeẏn $(2 \times)$, a zein $(1 \times)$, a zen $(1 \times)$, azen $(1 \times)$, aзejn $(1 \times)$

AGAIN: azen $(1 \times)$, azeyn $(1 \times)$, aзey்n $(1 \times)$
THINK: penke $(1 \times)$

THERE: per $(5 \times)$, per $(4 \times)$, per $(1 \times)$,

pere $(1 \times)$

WHERE: where $(2 x)$

THROUGH: porh $(15 \times)$, poru3 $(2 \times)$, proh

$(2 \times)$, pourh $(1 \times)$, pour3 $(1 \times)$

WHEN: whanne $(11 \times)$, when $(7 \times)$, whan

$(5 \times)$, whanne $(4 \times)$, whan $(3 \times)$, whenne $(2 \times)$, Whanne $(1 \times)$, when $(1 \times)$

ADDER: neddur $(2 \times)$, eddur $(1 \times)$, neddere $(1 \times)$, neddre $(1 \times)$, neddur $(1 \times)$ BOTH: bope $(2 \times)$

EITHER: eỷper $(3 \times)$

EYE pl.: eẏnen $(27 \times)$, eẏen $(2 \times)$, eynen $(1 \times)$, è̇nen $(1 \times)$, ẏзen $(1 \times)$

FIRE: fuỳre $(17 \times)$, fuỳr ( $3 \times)$, feỳre $(1 \times)$

FIRST: furst $(5 \times)$, frust $(1 \times)$, furste $(1 \times)$

FLESH: flesche $(1 \times)$, fleshe $(1 \times)$

GIVE: 3if $(17 \times)$, зeue $(12 \times)$, zef $(1 \times)$, 3it

$(1 \times)$

LITTLE: litul (5×), leẏtel (3×), litel ( $3 \times$ ), luẏtel (3×), lỳtel (3×), leẏtul (2×), lýtul $(1 \times)$, lỳtỳl $(1 \times)$

LIVE: lỳue $(2 \times)$, leue $(1 \times)$

OWN: oune $(5 \times)$

Past-participle prefix: $:^{13} \dot{\mathrm{y}}-(31 \times), \quad$ i$(10 \times), a-(1 \times)$

SOME: sum $(2 \times)$

SORROW: sorewe $(1 \times)$

YEAR: zer $(1 \times)$

13 It does not appear in the list of items supplied by LALME. 


\section{APPENDIX II}

LP 7460 (LALME, vol. 3, p. 172)

THESE: pese (bes, pis, puse)

THOUGH: pou3 (pau3)

IT: it

IF: zef (3if)

THEY: pei

AGAINST: azeyn (azeyns)

THEM: hem

AGAIN: azeyn

SUCH: suche, such ((syche))

THINK: penke

MANY: many (mony) ((meny))

WHERE: where

ANY: eny (any)

THROUGH: poro3, porow3, porow

MUCH: muche (myche)

(porou3)

ARE: bep (ben)

WHEN: whan, whenne, when (bo)

IS: is

WAS: wes

SHALL pl.: schulep, schulen (schullep)

SHOULD sg.: schulde

BOTH: bope

EITHER + OR: oper +

EYE $p l .:$ y3en, yen

FIRE: fuyr

FIRST: furst

GIVE: zef (зaf)

WOULD sg.: wolde

LITTLE: luytel, lytel

LIVE: lyf-

AFTER: aftur

THAN: pan

OwN: owene, owne

\section{APPENDIX III}

LP 7520 (LALME, vol. 3, pp. 174-175)

THESE: peose, pese (bis, peos, puse)

IS: is

IT: hit (it)

THEY: pay (bey)

THEM: hem

SUCH: suche

EACH: uche (eche)

MANY: many, monye, mony

ANY: any, ony

MUCH: muche, moche, meche

ARE: beon, beop (ben)

WAS: was

SHALL sg.: schal; $p l$. schullen (schullep)

SHOULD sg.: schulde (schul)

WILL sg.: wol; $p l$. wolen, wolep (wolun)

FROM: from, fro

AFTER: aftur

THAN: pan

THOUGH: pagh (bogh, paug3)

IF: $3 y f$ 


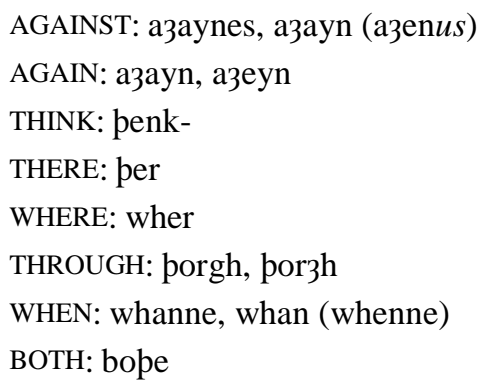

\author{
EYE pl.: yen \\ FIRE: fuyr \\ FIRST: furst \\ GIVE: zaf \\ LITTLE: luytul (litul) \\ LIVE: lyue \\ OWN: oune
}

\section{APPENDIX IV}

LP 7630 (LALME, vol. 3, p. 553)

\author{
THESE: peose, peos \\ IT: hit \\ THEY: pei, pey, heo, a \\ THEM: hem \\ SUCH: suche, such \\ EACH: vche, vch- \\ MANY: moni, mony (monye) \\ ANY: eny \\ MUCH: muchel, muche \\ ARE: beop, beb, ben \\ IS: is \\ WAS: was \\ SHALL sg.: schal; pl. schullen, schule, \\ schul \\ SHOULD sg.: schulde \\ WILL sg.: wole, wol; pl. wollen, wollep \\ WOULD sg.: wolde \\ FROM: from, fro \\ AFTER: aftur
}

\author{
THAN: pen \\ THOUGH: pauh (pouh) ((bau3, pous)) \\ IF: 3if \\ AGAINST: azeynes \\ AGAIN: azein, aзeyn \\ THINK: penke \\ THERE: per \\ WHERE: where, wher, wher-, whar- \\ THROUGH: porwh, porw \\ WHEN: whon ((when, whonne)) \\ BOTH: bope \\ EITHER + OR: oupur + \\ EYE pl.: ezen \\ FIRST: furste, furst \\ GIVE: 3 af \\ LITTLE: luytel, luyte, luttel, lutel \\ LIVE: liu-, liue \\ OWN: oune (owne)
}




\section{REFERENCES}

Benskin, Michael. 1991. The 'fit'-technique explained. In Felicity Riddy (ed.), Regionalism in late medieval manuscripts and texts: Essays celebrating the publication of A linguistic atlas of late mediaeval English, 9-26. Cambridge: D. S. Brewer.

Dawson, Warren R. (ed.). 1934. A leechbook or collection of medical recipes of the fifteenth century. London: Macmillan.

Dossena, Marina \& Roger Lass (eds.). 2004. Methods and data in English historical dialectology. Bern: Peter Lang.

Esteban-Segura, Laura. 2010. Dialectal study of a version of the Middle English Gilbertus Anglicus: The case of G.U.L. MS Hunter 509 (ff. 14r-167v). English Studies. A Journal of English Language and Literature 91(3): 256-273.

Esteban-Segura, Laura. 2012a. System of physic (GUL MS Hunter 509, ff. 1r-167v): A compendium of mediaeval medicine including the Middle English Gilbertus Anglicus. Bern: Peter Lang.

Esteban-Segura, Laura. 2012b. The Middle English Gilbertus Anglicus: An assessment of dialectal features in G.U.L. MS Hunter 307 (ff. 13r-145v). In Sara Martín Alegre \& Melissa Moyer \& Elisabet Pladevall \& Susagna Tubau (eds.), At a time of crisis: English and American studies in Spain, 323-328. Barcelona: Departament de Filologia Anglesa i de Germanística, Universitat Autònoma de Barcelona/AEDEAN.

Esteban-Segura, Laura. 2013. Some notes on London, Wellcome Library, MS 5262. In Rosario Arias et al. (eds.), Hopes and fears: English and American studies in Spain. Proceedings of the 36th AEDEAN Conference, 215-220. Málaga: Universidad de Málaga.

Jones, Claire. 2000. Vernacular literacy in late-medieval England: The example of East Anglian medical manuscripts. Ph.D. thesis, University of Glasgow. Available at http://theses.gla.ac.uk/633/ (Last accessed 15 March, 2013).

Laing, Margaret. 1989a. Introduction. In Margaret Laing (ed.), Middle English dialectology: Essays on some principles and problems, ix-xiv. Aberdeen: Aberdeen University Press.

Laing, Margaret. 1989b. Dialectal analysis and linguistically composite texts in Middle English. In Margaret Laing (ed.), Middle English dialectology: Essays on some principles and problems, 150-169. Aberdeen: Aberdeen University Press.

Laing, Margaret \& Keith Williamson (eds.). 1994. Speaking in our tongues: Medieval dialectology and related disciplines. Cambridge: D. S. Brewer.

Lass, Roger. 2004. Ut custodiant litteras: Editions, corpora and witnesshood. In Marina Dossena \& Roger Lass (eds.), Methods and data in English historical dialectology, 21-48. Bern: Peter Lang.

Mäkinen, Martti. 2004. Herbal recipes and recipes in herbals - intertextuality in early English medical writing. In Irma Taavitsainen \& Päivi Pahta (eds.), Medical and scientific writing in late medieval English, 144-173. Cambridge: Cambridge University Press.

Marqués-Aguado, Teresa. 2009. The dialectal provenance of G.U.L. MS Hunter 513. In Javier E. Díaz Vera \& Rosario Caballero (eds.), Textual healing: Studies in medieval English medical, scientific and technical texts, 109-121. Bern: Peter Lang.

McIntosh, Angus \& Michael L. Samuels \& Michael Benskin. 1986. A linguistic atlas of Late Mediaeval English. 4 vols. Aberdeen: Aberdeen University Press.

Miranda-García, Antonio \& Joaquín Garrido-Garrido. 2012. Text Search Engine (TexSEn). Málaga: Servicio de Publicaciones de la Universidad de Málaga. 
Mossé, Fernand. 1952. A handbook of Middle English. Baltimore and London: Johns Hopkins Press.

Ogden, Margaret Sinclair (ed.). 1938. The 'Liber de diversis medicinis' in the Thornton manuscript (MS. Lincoln Cathedral A.5.2.). Early English Text Society O.S. 207. London: Oxford University Press.

Riddy, Felicity (ed.). 1991. Regionalism in late medieval manuscripts and texts: Essays celebrating the publication of A linguistic atlas of late mediaeval English. Cambridge: D. S. Brewer.

Stenroos, Merja. 2004. Regional dialects and spelling conventions in late Middle English: Searches for (th) in the LALME data. In Marina Dossena \& Roger Lass (eds.), Methods and data in English historical dialectology, 257-285. Bern: Peter Lang.

Voigts, Linda E. \& Michael R. McVaugh. 1984. A Latin technical phlebotomy and its Middle English translation. Transactions of the American Philosophical Society 74/2: 1-6. 